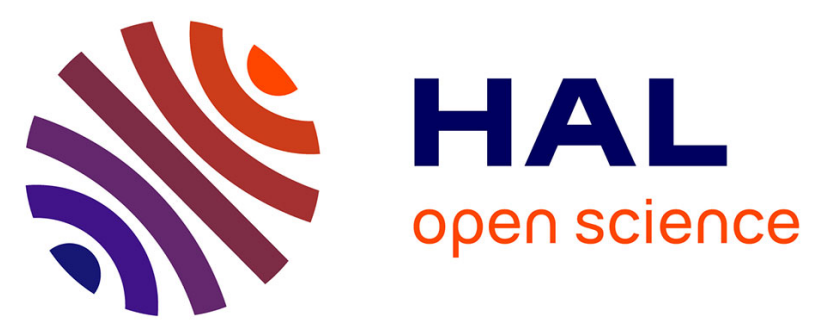

\title{
An Engineered Device for Indoleacetic Acid Production under Quorum Sensing Signals Enables Cupriavidus pinatubonensis JMP134 To Stimulate Plant Growth
}

Ana Zúñiga, Francisco de La Fuente, Fernán Federici, Corinne Lionne, Jérome Bônnet, Victor de Lorenzo, Bernardo González

\section{To cite this version:}

Ana Zúñiga, Francisco de La Fuente, Fernán Federici, Corinne Lionne, Jérome Bônnet, et al.. An Engineered Device for Indoleacetic Acid Production under Quorum Sensing Signals Enables Cupriavidus pinatubonensis JMP134 To Stimulate Plant Growth. ACS Synthetic Biology, 2018, 7 (6), pp.1519-1527. 10.1021/acssynbio.8b00002 . hal-02322555

\section{HAL Id: hal-02322555 \\ https://hal.science/hal-02322555}

Submitted on 30 Nov 2020

HAL is a multi-disciplinary open access archive for the deposit and dissemination of scientific research documents, whether they are published or not. The documents may come from teaching and research institutions in France or abroad, or from public or private research centers.
L'archive ouverte pluridisciplinaire HAL, est destinée au dépôt et à la diffusion de documents scientifiques de niveau recherche, publiés ou non, émanant des établissements d'enseignement et de recherche français ou étrangers, des laboratoires publics ou privés. 


\section{SyntheticBiology Penn}

Subscriber access provided by University of Pennsylvania Libraries

\section{Article}

\section{An engineered device for indoleacetic acid production under quorum sensing} signals enables Cupriavidus pinatubonensis JMP134 to stimulate plant growth

Ana Zuniga, Francisco De la Fuente, Fernan Federici, Corinne

Lionne, Jerome Bonnet, Victor de Lorenzo, and Bernardo Gonzalez

ACS Synth. Biol., Just Accepted Manuscript • DOI: 10.1021/acssynbio.8b00002 • Publication Date (Web): 10 May 2018

Downloaded from http://pubs.acs.org on May 15, 2018

\section{Just Accepted}

"Just Accepted" manuscripts have been peer-reviewed and accepted for publication. They are posted online prior to technical editing, formatting for publication and author proofing. The American Chemical Society provides "Just Accepted" as a service to the research community to expedite the dissemination of scientific material as soon as possible after acceptance. "Just Accepted" manuscripts appear in full in PDF format accompanied by an HTML abstract. "Just Accepted" manuscripts have been fully peer reviewed, but should not be considered the official version of record. They are citable by the Digital Object Identifier (DOI®). "Just Accepted" is an optional service offered to authors. Therefore, the "Just Accepted" Web site may not include all articles that will be published in the journal. After a manuscript is technically edited and formatted, it will be removed from the "Just Accepted" Web site and published as an ASAP article. Note that technical editing may introduce minor changes to the manuscript text and/or graphics which could affect content, and all legal disclaimers and ethical guidelines that apply to the journal pertain. ACS cannot be held responsible for errors or consequences arising from the use of information contained in these "Just Accepted" manuscripts. 


\title{
An engineered device for indoleacetic acid production under quorum sensing signals enables Cupriavidus pinatubonensis JMP134 to stimulate plant growth
}

\begin{abstract}
Ana Zúñiga ${ }^{1,2 *}$, Francisco de la Fuente ${ }^{1,3}$, Fernán Federici ${ }^{4}$, Corinne Lionne ${ }^{2}$ Jérome Bônnet ${ }^{2}$, Victor de Lorenzo ${ }^{5}$ and Bernardo González ${ }^{1}$
\end{abstract}

Affiliations:

${ }^{1}$ Facultad de Ingeniería y Ciencias, Universidad Adolfo Ibáñez - Center of Applied Ecology and Sustainability, Santiago de Chile, Chile.

${ }^{2}$ Centre de Biochimie Structurale, INSERM U1054, CNRS UMR5048, University of Montpellier, Montpellier, France.

${ }^{3}$ R2B catalyst, Research Center, Andrés Bello 2299, Santiago, Chile.

${ }^{4}$ Departamento de Genética Molecular y Microbiología, Facultad de Ciencias Biológicas, Pontificia Universidad Católica de Chile, Santiago, Chile, Fondo de Desarrollo de Áreas Prioritarias, Center for Genome Regulation, Millennium Institute for Integrative Systems and Synthetic Biology, Pontificia Universidad Católica de Chile, Santiago, Chile.

${ }^{5}$ Centro Nacional de Biotecnología, Madrid, Spain.

*To whom correspondence should be addressed: Ana Zúñiga ana.zuniga@cbs.cnrs.fr. 


\begin{abstract}
The environmental effects of chemical fertilizers and pesticides have encouraged the quest for new strategies to increase crop productivity with minimal impacts on the natural medium. Plant growth promoting rhizobacteria (PGPR) can contribute to this endeavor by improving fitness through better nutrition acquisition and stress tolerance. Using the neutral (non PGPR) rhizobacterium Cupriavidus pinatubonensis JMP134 as the host, we engineered a regulatory forward loop that triggered the synthesis of the phytohormone indole-3-acetic acid (IAA) in a manner dependent on quorum sensing (QS) signals. Implementation of the device in JMP134 yielded synthesis of IAA in an autoregulated manner, improving the growth of the roots of inoculated Arabidopsis thaliana. These results not only demonstrated the value of the designed genetic module, but also validated C. pinatubonensis JMP134 as a suitable vehicle for agricultural applications, as it is amenable to genetic manipulations.
\end{abstract}

KEYWORDS: Arabidopsis thaliana; Cupriavidus pinatubonensis; quorum sensing; synthetic beneficial interaction. 
Microorganisms are one of the most strategic resources for overcoming the problems produced by excessive application of chemical fertilizers and pesticides in agriculture ${ }^{1}$. In particular, plant growth promoting rhizobacteria (PGPR), a well characterized group of biological fertilizers, increase the acquisition of nutrients, modify plant hormone levels, and protect the host from pathogen agents ${ }^{2-4}$. However, to properly generate beneficial effects on plants, a better understanding of the particular features of beneficial bacteria and their interactions with host plants and with other microorganisms is required. For example, the expression of genes involved in plant growth promotion mechanisms by PGPRs changes according to biotic and abiotic factors of the rhizosphere ${ }^{5}$. Yet, it is estimated that up to $90 \%$ of PGPRs inoculated in legume crops yield almost no effect, an observation explained by low viability of these bacteria in the soil ${ }^{6}$. For this reason, field inoculation with different PGPR strains in plants of agronomic interest often shows discrepancies with in vitro results, evidenced by a decrease in root colonization, as well as inconsistent effects on plant growth, calling into question the effectiveness of PGPR applications in agriculture ${ }^{5,7}$. The use of PGPR members with different plant growth promotion strategies, a PGPR consortium, is a common approach to generate synergistic effects in inoculated plants 5,8 . However, interactions between inoculated bacterial strains may yield unexpected effects due to competition or crosstalk, affecting plant colonization, bacterial gene expression, and consequently, beneficial effects. Among the important bacterial traits for plant colonization are motility and quorum sensing (QS), which confer competitive advantages and promote survival in a particular niche ${ }^{2,9}$. In this context, QS has an important role in host colonization because it regulates genes involved in cooperative traits ${ }^{10,11}$. Using the QS system, bacteria are able to sense their population via self-inducing molecules, which activate a response only when population density, and therefore the signal molecule in the extracellular environment, is high ${ }^{10}$. QS regulates numerous key processes relevant to biotechnological applications, including biofilm formation, catabolic gene expression, biosurfactant production, 
and exopolysaccharide synthesis ${ }^{12,13}$. The homoserine lactone (HSL) QS system has been used to engineer novel behaviors in bacteria with predictive gene expression response to HSL signal concentration ${ }^{14-16}$. QS has been also used to synchronize gene expression in a population, thereby mitigating intrinsic population variability and improving the yields in engineered strains ${ }^{16}$. The QS based strategy is particularly interesting in PGPRs because their activity at plant roots is a consequence of all active cells expressing a particular gene involved in plant growth promotion. As such, if key traits are regulated by a QS system, their contribution would be observed only when the population reaches a significant, specific density, i.e. when bacteria are able to colonize the plant roots.

In this study, we aimed to engineer the neutral (non -PGPR) rhizobacteria Cupriavidus pinatubonensis JMP134 to produce a synthetic plant growth promoting bacterium capable of coordinating the expression of genes involved in a particular beneficial effect on plant through a HSL-QS system. C. pinatubonensis JMP134 has distinct advantages in the rhizosphere because it can metabolize some components of plant root exudates, allowing the bacteria to colonize root surfaces ${ }^{17}$. We introduced a positive feedback QS circuit in $C$. pinatubonensis JMP134 to induce gene expression in a cell density dependent manner. The population harboring the plasmid with this construct activates gene expression at a level similar to induction with HSL, as measured by GFP fluorescence. The introduced construct enables regulation of the expression of the IAA synthesis genes in strain JMP134, which is coordinated by an increase in the bacterial population density at the root level. Our study reports characterization of a synthetic QS system in C. pinatubonensis JMP134 and points to a promising model for biotechnological applications, as the strain can readily undergo genetic modifications and transformation and is intrinsically receptive to gene expression control by QS.

\section{RESULTS AND DISCUSSION}




\section{C. pinatubonensis JMP134 as a host for synthetic QS networks and beneficial plant-bacteria interactions.}

C. pinatubonensis JMP134 belongs to the Burkholderiales order and is wellcharacterized due to its catabolic features, especially those related to the degradation of aromatic compounds ${ }^{18}$. Although several HSL based quorumsensing systems have been identified in Burkholderiales strains, none of them have been detected in strain JMP134 ${ }^{18,19}$. This feature makes this strain a good host in which to construct and apply different genetic circuits controlled by synthetic HSL-QS systems. We chose the well-characterized Luxl/LuxR-type QS system because of its simplicity, standardization, and frequent application in synthetic biology ${ }^{15,16,20,21}$. Analysis of the strain's genome revealed no ORFs with significant identities to putative luxl and luxR genes of the Vibrio fischeri QS system. We also confirmed the lack of a functional HSL QS system in strain JMP134, as no HSL production was detected by thin-layer chromatography in supernatants from stationary growth phase (Supplementary Figure S1). This strain is also particularly interesting to test for improvement of the plant-bacteria interaction because it colonizes plant rhizosphere and degrades plant root exudates components ${ }^{17,22}$. Besides its ability to grow and colonize plant roots without any adverse effect for host, this bacterium does not possess putative genes involved in the promotion of plant growth and its interactions with plants are considered to be neutral ${ }^{17}$. For these reasons, we chose the strain JMP134 to engineer a synthetic beneficial plant-bacteria interaction.

\section{Characterization of a Lux-like QS system in C. pinatubonensis JMP134 to create an autoinducible regulation of gene expression.}

A genetic circuit with a positive feedback for cell density-dependent control of gene expression was constructed with the QS system from marine bacterium $V$. fischeri ${ }^{10,23,24}$. Iuxl and luxR genes and $\mathrm{P}_{\text {lux }}$ promoter, identified as a key elements 


\section{Table 1}

Bacterial strains and plasmids used in this study

\begin{tabular}{|c|c|c|}
\hline Strain or plasmid & Relevant phenotype and/or genotype & $\begin{array}{l}\text { Reference or } \\
\text { source }\end{array}$ \\
\hline \multicolumn{3}{|l|}{ Strains } \\
\hline $\begin{array}{l}\text { C. pinatubonensis } \\
\text { JMP134 }\end{array}$ & Benzoate $^{+}$, Fructose $^{+}, \mathrm{IAA}^{-}, \mathrm{HSL}^{-}$ & $\begin{array}{l}\text { DSMZ (Lykidis } \\
\text { et al., 2010) }\end{array}$ \\
\hline E. coli Mach & $\begin{array}{l}\Delta \text { recA1398 endA1 tonA } 80 \Delta \text { lacM15 } \Delta \text { lacX74 } \\
\text { hsdR(rK mK ) }\end{array}$ & $\begin{array}{l}\text { Invitrogen, } \\
\text { Carlsbad, CA, } \\
\text { USA }\end{array}$ \\
\hline \multicolumn{3}{|l|}{ Plasmids } \\
\hline pSEVA637 & $\mathrm{Gm}^{\mathrm{R}}$; oriV(PBR1); GFP & $\begin{array}{l}\text { Martinez-García } \\
\text { et al., }\end{array}$ \\
\hline pSEVA-P $P_{\text {luxl }}-G F P$ & $\mathrm{Gm}^{\mathrm{R}} ; \mathrm{P}_{\text {lux }}-\mathrm{GFP} ;$ oriV(PBR1) & This study \\
\hline pSEVA-P $P_{|u x|}-|u x|-G F P$ & $\mathrm{Gm}^{\mathrm{R}} ; \mathrm{P}_{\text {lux }}$-luxl-GFP; oriV(PBR1) & This study \\
\hline $\begin{array}{l}\text { pSEVA-P } P_{\text {lux| }}-I u x I-I A A- \\
\text { GFP }\end{array}$ & $\begin{array}{l}\mathrm{Gm}^{\mathrm{R}} ; \mathrm{P}_{\text {lux }}-\text { luxl- laaH-laaM-GFP; oriV(PBR1); } \\
\mathrm{IAA}^{+}\end{array}$ & This study \\
\hline $\begin{array}{l}\text { pSB1C3- } \\
\text { BBa_K515100 }\end{array}$ & $\mathrm{Cm}^{\mathrm{R}} ; \mathrm{P}_{\text {veg }}$-laaH-laaM from $P$. savastanoi & $\begin{array}{l}\text { BioBrick } \\
\text { Repository } \\
\text { Spring } 2014 \\
\text { Distribution }\end{array}$ \\
\hline $\begin{array}{l}\text { pSB1C3- } \\
\text { BBa_K516011 }\end{array}$ & $\mathrm{Cm}^{\mathrm{R}}$; RBS-IuxI (Synthesizes 3-oxo-C6-HSL) & $\begin{array}{l}\text { BioBrick } \\
\text { Repository } \\
\text { Spring } 2014 \\
\text { Distribution }\end{array}$ \\
\hline pSB3K3-BBa_F2620 & $\mathrm{Km}^{\mathrm{R}} ; \mathrm{P}_{\text {tet }}-/ \mathrm{lu} R-\mathrm{P}_{\text {lux }} ;$ oriV $(\mathrm{P} 15 \mathrm{~A})$ & $\begin{array}{l}\text { Canton et al., } \\
2008\end{array}$ \\
\hline
\end{tabular}

Abbreviations used in this table are as follows: $\mathrm{Gm}$, gentamicin; $\mathrm{Cm}$, chloramphenicol; $\mathrm{Km}$, kanamycin; GFP gene encoding a green fluorescent protein; laaH gene encoding indole-3acetamide hydrolase; laaM gene encoding 2-tryptophan monooxygenase; luxl gene encoding homoserine lactone synthase; $\mathrm{IAA}^{+}$ability to produce indole-3-acetic acid. 
of QS system in this bacterium, have been used previously to construct artificial cell-to-cell communication systems ${ }^{14,24-27}$. We constructed a genetic circuit able to produce and respond to N-(3-Oxohexanoyl)-L-homoserine lactone, 3-oxo-C6$\mathrm{HSL}$, increasing the transcription of target gene, GFP (Fig. 1A). The strain harboring this circuit was called $\mathrm{P}_{\text {lux }}-/$ luxl-GFP (Figure $1 \mathrm{~A}$ ), and was able to synthesize 3-oxo-C6-HSL (Supplementary Figure S1). We also constructed a control strain harboring a genetic circuit with inducible expression of GFP by 3oxo-C6-HSL; this strain was called $\mathrm{P}_{\mathrm{lux}}$-GFP. To characterize the behavior of these circuits, we measured GFP expression in each strain using a fluorescence plate reader and a flow cytometer. We calculated the output of the circuits in strain JMP134 using the relative measurements of each circuit normalized by the fluorescence of wild type strain JMP134 with the pSEVA-GFP plasmid but without the promoter (Figure 1B). The dynamic response of the $\mathrm{P}_{\text {lux }}$-luxl-GFP strain suggested a cell density-dependent curve of GFP production after $10 \mathrm{~h}$. of growth which corresponds to an optical density at $600 \mathrm{~nm}\left(\mathrm{OD} 6_{00 \mathrm{~nm}}\right)$ of 0.23 , indicating a positive-feedback loop in the synthesis of 3-oxo-C6-HSL (Figures 1B and $1 \mathrm{C}$ ). This response was similar to the fluorescence curve observed in the strain $\mathrm{P}_{\text {lux }}$ GFP in the presence of $1 \mu \mathrm{M}$ of 3-oxo-C6-HSL between 9 and 17 hours of growth. A delay was observed in the growth curve of strain $P_{\mathrm{lux}}$-GFP induced with 3-oxo-C6-HSL compared with the non-induced strain (Figure 1C). The growth curve also showed an earlier stationary phase attained by the strain $\mathrm{P}_{\text {lux }}$-luxl-GFP compared to the strain $\mathrm{P}_{\text {lux }}$-GFP, induced or not with 3-oxo-C6HSL. This phenomenon might reflect the metabolic burden of the device expression in the growth of the strain JMP134 ${ }^{28}$. We did not observe any GFP production from the control strain in the absence of 3-oxo-C6-HSL (Figure 1B). Likewise, the strain JMP134 harboring a control circuit named $\mathrm{P}_{\text {lux }}$-rhll-GFP with a constitutive expression of luxR, and an inducible expression of rhll (for $\mathrm{N}$ butyryl-L-homoserine lactone synthase and C4-HSL synthesis) and GFP genes by 3-oxo-C6-HSL, was unable to produce GFP without the induction of 
exogenous 3-oxo-C6-HSL (Supplementary Figure S2), which corroborated the device synthesis of 3-oxo-C6-HSL and its orthogonality in the strain JMP134.

In general, the signaling mediated by HSL and QS activation in the population is attributed principally to the number of cells and the volume available for growth. Both factors can vary independently and affect the final cell density at which the positive feedback loop is activated ${ }^{12}$. Based on this criterion we analyzed the device induction in the strains $P_{\text {lux }}$-GFP and $P_{\text {lux }}$-luxl-GFP, grown in a flask after its synchronization, induced or not with $1 \mu \mathrm{M}$ of 3 -oxo-C6-HSL, by flow cytometry. The analysis showed a clear difference in the signal of GFP produced by the strain $\mathrm{P}_{\text {lux }}$-luxl-GFP, after reaching an $\mathrm{OD}_{600 \mathrm{~nm}}$ of 0.3 (Figure $2 \mathrm{~A}$ ). Those strains induced with $1 \mu \mathrm{M}$ 3-oxo-C6-HSL produced 20 and 60 times more GFP signal at $\mathrm{OD}_{600 \mathrm{~nm}} 0.1$ than the non-induced strains $\mathrm{P}_{\text {lux }}-$ luxl-GFP and $\mathrm{P}_{\text {lux }}-\mathrm{GFP}$, respectively (Figure 2A). The device expression in the strain $\mathrm{P}_{\mathrm{lux}}$-luxl-GFP was slightly leaky, producing differences in the signal of GFP in the population. The positive feedback loops from diverse bacteria have this behaviour by nature, which is desirable depending of the environment condition ${ }^{29-31}$. Here, the strain $\mathrm{P}_{\text {lux }}$-luxl-GFP showed a complete synchronization in GFP signal, after reaching an $\mathrm{OD}_{600 \mathrm{~nm}} 0.4$ (Figure $2 \mathrm{~A}$ ). It means that in these growth conditions, the population of the strain $\mathrm{P}_{\text {lux }}-$-luxl-GFP was able to produce enough amount of autoinducer to synchronize the entire population to produce GFP signal at the same level. We also confirmed this phenomenon observing the levels of expression of homoserine lactone synthase protein Luxl by SDS-PAGE, which was detectable only after $\mathrm{OD}_{600 \mathrm{~nm}} 0.6$ (Supplementary Figure S4). The regulation of QS system in environments include a variety of factors that affect principally the autoinducer molecule and the signalling process ${ }^{32}$. In general it is assumed that a synchronous expression of genes is due to a density-dependent regulatory process in the population ${ }^{33}$. But now, the spatial distribution of cells is also considered, giving importance to the diffusion sensing ${ }^{34}$. Therefore the genesis, diffusion, interception, as well as degradation produced by HSL-degradation enzymes (quorum quenching ( $Q Q)$ enzymes) are involved in the complex 
regulatory network which influences the synthesis and accumulation of autoinducer signals within bacterial cells ${ }^{12,32,35,36}$. Here we obtained a simplified autoinducer device able to synchronize the gene expression of GFP in the strain JMP134 by a positive feedback loop after an $\mathrm{OD}_{600 \mathrm{~nm}} 0.4$, corresponding to a middle exponential phase of growth. This type of autoinduction can be useful in complex environments, as the rhizosphere, in which the spatial distribution of bacteria is not homogenous and small clusters of cells could be synchronized readily although the temporal changes in the diffusion rate and nutrient availability as it has been described by Hense et al., 2007.

QS dependent IAA biosynthesis in C. pinatubonensis JMP134 creates a synthetic beneficial interaction with $A$. thaliana.

Plant beneficial bacteria promote plant growth through a variety of mechanisms ${ }^{22,37-40}$. One such mechanism is the synthesis of auxins, in particular the indole-3acetic acid (IAA), which is involved in root proliferation ${ }^{41-46}$. In bacteria, IAA is synthesized from tryptophan, which is found at different concentrations in root exudates depending on the plant genotype ${ }^{5,47}$. Because we were interested in building synthetic beneficial plant-bacteria interaction with an autoinducible expression of beneficial target genes, we constructed an IAA QS dependent biosynthesis device in strain JMP134. We used 2-tryptophan monooxygenase ( $i a a M$ gene) and indole-3-acetamide hydrolase (iaaH gene) enzymes from the Ltryptophan-dependent indole-3-acetamide biosynthesis pathway from Pseudomonas savastanoi ${ }^{48}$. We assembled both genes downstream the $\mathrm{P}_{\text {lux }}-$ luxl sequence in the plasmid pSEVA- $P_{\text {lux }}$-luxl, creating the new plasmid $\mathrm{P}_{\text {lux }}$-luXI-IAAGFP (Fig. 1A). The flow cytometry analysis of the strain harboring the plasmid $P_{\text {lux }}$-luxI-IAA-GFP, showed a feedback loop activation after the strain reached an $\mathrm{OD}_{600 \mathrm{~nm}}$ of 0.5 of growth, but only after an $\mathrm{OD}_{600 \mathrm{~nm}}$ of 1.0 the GFP signal in the population was completely synchronized (Figure 2B, Supplementary Figure S3). However, the GFP signal in this strain was less than those observed in the strain $\mathrm{P}_{\text {lux }}$-luxl-GFP at $\mathrm{OD}_{600 \mathrm{~nm}}$ of 0.5 (Figure 2, Supplementary Figure $\mathrm{S} 3$ and Table 2), even in presence of $1 \mu \mathrm{M}$ of 3-oxo-C6-HSL, due probably to the metabolic 
burden produced by the expression of device genes in the growth strain. The levels of expression for Luxl, laaM and laaH proteins were confirmed by a SDSPAGE in the strain $\mathrm{P}_{\text {lux }}$-luxl-IAA-GFP and presented a slightly overexpression in extract of protein from cultures at $\mathrm{OD}_{600 \mathrm{~nm}}$ of 1.0 (Supplementary Figure S4).

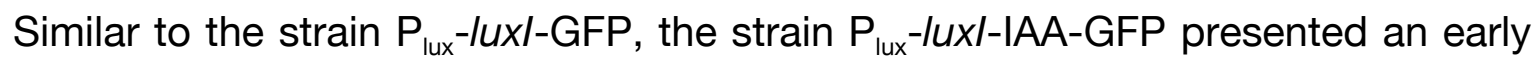
stationary phase of growth after the device expression, compared to the curve from wild type and $P_{\text {lux }}$-GFP strains (Supplementary Figure S5) indicating as well, the metabolic burden of the device expression in the growth of this strain ${ }^{28}$. Nevertheless, the synthesis of $330 \mu \mathrm{M}$ of IAA was confirmed by a highperformance liquid chromatography UV detection (HPLC-UV) $1 \mathrm{~h}$ after the addition of $1 \mathrm{mM}$ of tryptophan as a precursor, in the strain $\mathrm{P}_{\text {lux }}$-luxl-IAA-GFP, only after reaching an $\mathrm{OD}_{600 \mathrm{~nm}}$ of 0.6 of growth. No IAA synthesis was detected at $\mathrm{OD}_{600 \mathrm{~nm}}$ of 0.2 in presence of tryptophan, confirming the autoinduction of the device only at higher $\mathrm{OD}_{600 \mathrm{~nm}}$ (Supplementary Figure S6).

To test if the synthesis of IAA in strain JMP134 enables it to promote plant growth, we inoculated Arabidopsis thaliana plants with the strain $\mathrm{P}_{\text {lux }}$-luxI-IAAGFP. After 14 days of growth we evaluated parameters related to auxin effects in plants. Significant effects were observed in lateral root number, primary root length, fresh weight, and rosette area of inoculated plants (Figure 3A, Supplementary Figure S7 and Supplementary Table T3 ). As reported previously 17, the wild type and $P_{\text {lux }}$-luxl-GFP strains were not able to modify growth of $A$. thaliana plants in any of the parameters measured above (Figure 3A, Supplementary Figure S7). It is know that small-chain (C6 and C8) HSLs do not produce any effect on root architecture of $A$. thaliana plants, as we confirmed in plants inoculated with $\mathrm{P}_{\text {lux }}$-luxl-GFP strain ${ }^{49}$. A large proportion of microorganisms isolated from the rhizosphere possesses the ability to synthesize and release auxins as secondary metabolites ${ }^{50}$. The positive effect of bacterial IAA production on plants has been well documented in Bradyrhizobium and Azospirillum ${ }^{51,52}$. IAA enhances root development, facilitating nutrient uptake ${ }^{3,53}$ 
as we observed in plants inoculated with strain $\mathrm{P}_{\text {lux }}$-luxl-IAA-GFP (Figure 3A, Supplementary Figure S7). At the plant root level, IAA softens the cell wall rigidity, thereby increasing the amount of plant root exudates and providing additional nutrients to support bacterial growth ${ }^{3,54}$. Several aromatic compounds are present in plant root exudates which can be metabolized by aromatic ring cleavage pathways that converge in the formation of a-ketoadipate, an intermediate that can be incorporated into the central metabolism ${ }^{17,55}$. The use of this pathway by C. pinatubonensis JMP134 is important for growth at plant root surfaces and subsequent plant rhizosphere colonization ${ }^{17}$. To address the root colonization of $\mathrm{P}_{\text {lux }}$-luxI-IAA-GFP and the in vivo expression of IuxI-IAA-GFP synthetic operon, we evaluated GFP expression in the roots of a transgenic line of $A$. thaliana. We created an in vivo red fluorescent marker for plants that enables an experimental design using GFP-based markers in bacteria. This reporter labels plant membrane through a membrane-tagged protein LTI6b At3g05890 ${ }^{56,57}$ fused to the red fluorescent protein mKate2 ${ }^{58}$. We observed a homogeneous pattern of colonization at the surface of roots by strain $\mathrm{P}_{\text {lux }}$-luxlIAA-GFP, principally at the root tip and surrounding hair roots (Figure 3D). The same pattern was observed in roots inoculated with the $\mathrm{P}_{\text {lux }}$-luxl-GFP strain (Figure 3C). We used the wild type strain JMP134 without any fluorescent reporter system as a control of roots colonization. The number of cells at the plant roots was similar in wild type strain JMP134 (5.65 $\pm 0.7 \log _{10}$ colony forming units (CFU)/mg fresh weight (FW)) and strains $P_{\text {lux }}$-luxl-IAA-GFP $\left(4.51 \pm 0.9 \log _{10}\right.$ $\mathrm{CFU} / \mathrm{mg} \mathrm{FW})$ and $\mathrm{P}_{\text {lux }} / \mathrm{luxl}$-GFP $\left(5.93 \pm 1.2 \log _{10} \mathrm{CFU} / \mathrm{mg} \mathrm{FW}\right), 14$ days postinoculation. As PGPR display more than one mechanism to promote plant growth, it is difficult to determine the real impact of bacterial IAA biosynthesis on plant growth ${ }^{5}$. However, our results demonstrate that IAA synthesis alone is able to promote growth in $A$. thaliana through an engineered synthetic beneficial plantbacteria interaction. In conclusion we have demonstrated the value of the autoiducible device to synthesize IAA in plants, but also validated C. pinatubonensis JMP134 as a 
suitable vehicle for agricultural or soil remediation applications, as it is amenable to genetic manipulations.

\section{METHODS}

\section{Strains and media}

C. pinatubonensis JMP134 was obtained from Deutsche Sammlung von Mikroorganismen und Zellkulturen $\mathrm{GmbH}$, Braunschweig (DSMZ), Germany. Strain JMP134 wild type and its derivatives were grown at $30^{\circ} \mathrm{C}$ in mineral salt medium Dorn ${ }^{59}$, supplemented with $10 \mathrm{mM}$ benzoate or fructose and the addition of gentamicin $\left(\mathrm{Gm} ; 30 \mathrm{gg} \mathrm{ml}^{-1}\right)$, when required. Escherichia coli Mach (Invitrogen, Carlsbad, CA, USA) cells were grown at $37^{\circ} \mathrm{C}$ in Luria Bertani (LB) medium and used as hosts for cloning procedures. Growth biomass tests were measured at an optical density at $600 \mathrm{~nm}\left(\mathrm{OD}_{600}\right)$ and three replicates were performed for each growth measurement.

\section{Plasmid construction}

Plasmids used in this study are listed in Table 1. We used the composite device BBa_F2620 for constitutive expression of luxR ${ }^{60}$, assembled in a Standard European Vector Architecture (pSEVA) vector with a RBS and a promoter-less green fluorescent protein (GFP) cargo, pSEVA637 ${ }^{61,62}$. pSEVA plasmids have an optimal architecture for construction of complex prokaryotic phenotypes and are commonly used to engineer environmental Gram negative bacteria ${ }^{62-65}$. All plasmids were assembled in pSEVA637 ${ }^{61,62}$, using the Gibson assembly method ${ }^{66}$. Each DNA fragment was obtained by PCR using oligonucleotides, ordered from Sigma-Aldrich Co. (St. Louis, MO, USA), and listed in Supplementary Table 1. To obtain the pSEVA-P $P_{\text {lux }}$-GFP plasmid, we amplified the entire DNA fragment containing $P_{\text {tet }}$ promoter, luxR gene and $P_{\text {lux }}$ promoter from BBa_F2620 standard part from BioBrick Repository (primer numbers 1-2). These primers contain a 20bp terminal sequence homologous to the terminus of the pSEVA637 fragment 
(primer numbers 3-4) to be linked by Gibson assembly. To obtain the PSEVA-P $\mathrm{Iux}$ IuxI-GFP plasmid, we assembled the amplified luxl gene from BBa_K516011 standard part from BioBrick Repository (primer numbers 5-6) and DNA fragment from pSEVA-P $P_{\text {lux }}-$ GFP using primers 3-7. Finally, to obtain the plasmid pSEVA$P_{\text {lux }}$-IUXI-IAA-GFP we assembled the amplified gene sequences iaaM and iaaH from BBa_K515100 standard part from BioBrick Repository (primer numbers 8-9) and DNA fragment from pSEVA-P $P_{\text {lux }}$-luxl-GFP using primers 3-10. All plasmid constructs were confirmed by Sanger DNA sequencing (Macrogen, Korea). Plasmids were electroporated in C. pinatubonensis JMP134 and selected in LB medium with antibiotic.

\section{Plate reader fluorescence and flow cytometry analysis}

For plate reader experiments, $2 \mathrm{~mL}$ culture of Dorn minimal medium supplemented with $10 \mathrm{mM}$ fructose and $30 \mu \mathrm{g} \mathrm{ml}{ }^{-1}$ gentamicin (for strain harboring different versions of PSEVA plasmids) were inoculated with single colonies of strains from a freshly streaked plate of Dorn minimal medium with 10 $\mathrm{mM}$ benzoate. Cultures were grown for $15 \mathrm{~h}$ at $30^{\circ} \mathrm{C}$ with shaking. Then, the cultures were washed once in fresh medium and diluted until $\mathrm{OD}_{600 \mathrm{~nm}} 0.05$ in 5 $\mathrm{mL}$ fresh medium and grown to an $\mathrm{OD}_{600} \mathrm{~nm} 0.1$ under the same conditions. Subsequently, $200 \mu \mathrm{l}$ aliquots of each of the cultures were transferred into a flatbottomed 96 well plate (Cellstar Uclear bottom, Greiner Bio-One, Solingen, Germany) and $2 \mu \mathrm{l}$ of $100 \mu \mathrm{M}$ of 3-oxo-hexanoyl-homoserine lactone (3-oxoC6HSL) (Sigma-Aldrich, St. Louis) were added to each well. Six replicate wells were measured for each treatment. Three wells were each filled with $200 \mu \mathrm{l}$ of medium to measure the absorbance background. The plate was incubated in a synergyMX well-plate reader (Biotek, Bad 21 Friedrichshall, Germany) at $30^{\circ} \mathrm{C}$ and assayed with an automatically repeating protocol of absorbance measurements (600 nm absorbance filter) and fluorescence measurements (488 $\mathrm{nm}$ excitation filter, $525 \mathrm{~nm}$ emission filter) for $20 \mathrm{~h}$, with $1 \mathrm{~h}$ between repeated measurements. For flow cytometry analysis, single colonies of strains from a 
freshly streaked plate of Dorn minimal medium with $10 \mathrm{mM}$ benzoate were grown overnight at $30^{\circ} \mathrm{C}$ with shaking in Dorn minimal medium with $10 \mathrm{mM}$ fructose. Cells were washed twice with fresh medium and diluted in $20 \mathrm{~mL}$ of fresh medium with fructose until $\mathrm{OD}_{600 \mathrm{~nm}} 0.01$ and incubated until the cultures reached $\mathrm{OD}_{600 \mathrm{~nm}}$ 0.1. At this point, cells were divided into two samples: one was induced by the addition of $1 \mu \mathrm{M}$ 3-oxo-C6HSL, and the other was kept as a non-induced. Cultures were incubated as described above and an aliquot of each sample was withdrawn every hour after induction. A MACSQuantTM VYB cytometer (Miltenyi Biotec, Bergisch Gladbach, Germany) was used for GFP analysis. The flow cytometry analysis was carried out on at least 20,000 cells and the data was processed using FlowJo v.10.0.8 software (FlowJo LLC, Ashland, OR, USA).

\section{SDS-PAGE}

In order to determine the expression of Luxl, laaM and laaH proteins, we run a SDS-PAGE from culture of strains $\mathrm{P}_{\text {lux }}$-luxl-GFP and $\mathrm{P}_{\text {lux }}$-luxl-IAA-GFP at $\operatorname{anOD}_{600 \mathrm{~nm}}$ of $0.2,0.6$ and 1 . The cultures were centrifuged at $13,000 \mathrm{xg}$ for 10 minutes to collect the cells. The pellets were weighted and $10 \mathrm{mg}$ were used for cell extract preparation in $50 \mu \mathrm{L} 1 \times$ SDS sample buffer and heated at $95^{\circ} \mathrm{C}$ for 10 minutes. After centrifugation for 10 minutes at $13,000 \times g, 5 \mu \mathrm{L}$ of the denatured sample was fractionated by SDS-PAGE in Novex wedgewell 4-12\% Tris-Glycine gel (Invitrogen).

\section{Measurement of IAA synthesis}

In order to determine the IAA synthesis we grew the strain P lux -luxI-IAA-GFP in 50 $\mathrm{mL}$ of minimal medium with $10 \mathrm{mM}$ of fructose as carbon source, until an $\mathrm{OD}_{600 \mathrm{~nm}}$ of 0.2 and 0.6 and then we exposed the cells to $1 \mathrm{mM}$ of tryptophan for $3 \mathrm{~h}$. Cells were centrifuged at $5.000 \times \mathrm{g}$. The supernatant containing IAA was filtered (filter unit of $0.22 \mathrm{~nm}$ pore diameter) and its $\mathrm{pH}$ was adjusted to 2.5 using hydrochloric acid. The IAA was extracted from the aqueous medium with 1 volume of ethyl acetate (two times). The pooled organic layer was dried over anhydrous $\mathrm{Na}_{2} \mathrm{SO}_{4}$ 
and filtered, and the solvent rotary evaporated. The samples were resuspended in ethyl acetate at 10X and diluted in buffer $40 \%$ methanol- $60 \% \mathrm{H}_{2} \mathrm{O}$ containing $0.1 \%$ (vol/vol) phosphoric acid. The presence of IAA was determined by highperformance liquid chromatography-UV detection (HPLC-UV) from $20 \mu \mathrm{L}$ of the sample, injected into Agilent Technologies 1260 Infinity II LC System (Agilent Technologies, Les Ulis, France) equipped with a Kromasil 100-3.5 C18 4.6 x 150 $\mathrm{mm}$ column. Methanol- $\mathrm{H}_{2} \mathrm{O}$ mixtures containing $0.1 \%$ (vol/vol) phosphoric acid were used as the solvent, at a flow rate of $0.75 \mathrm{ml} / \mathrm{min}$. The column effluent was monitored at $210 \mathrm{~nm}$. Retention time for IAA methanol- $\mathrm{H}_{2} \mathrm{O}$ (40:60) solvent IAA was $14.4 \mathrm{~min}$. A calibration curve was achieved by injection of $20 \mu \mathrm{L}$ of IAA at 0.1 to $100 \mu \mathrm{M}$.

\section{Plants construction, inoculation and growth parameters}

A. thaliana ecotype Col-0 and the A. thaliana transgenic line 35S:mKate-LTI6bNosT were used. 35S:mKate-LTI6b-NosT was created by assembling $35 \mathrm{~S}$ promoter (PCR-amplified from ${ }^{67}$, mKate2 (PCR-amplified from ${ }^{68}$ ) and LTI6b gene (PCR-amplified from 35S::EGFP-LTI6b; ${ }^{57}$ ) into pGreenll backbone by Gibson Assembly ${ }^{66}$. This vector was then used to transform $A$. thaliana using the floral dip method ${ }^{69}$. Seeds were surface sterilized with $50 \%$ (vol/vol) commercial chlorine bleach for $7 \mathrm{~min}$ and washed three times in sterile distilled water. Then they were kept at $4^{\circ} \mathrm{C}$ for 2 days in the absence of light to produce stratification. After that, seeds were sown in sterile plastic Petri dishes with $1 \%$ agar plates containing MS basal salt mixture (Sigma-Aldrich, St. Louis) inoculated or not inoculated with bacteria. Strains JMP134 wt, $\mathrm{P}_{\text {lux }}-$ lux-GFP, and $\mathrm{P}_{\text {lux }}-$ lux-IAA-GFP were adjusted to approximately $10^{4} \mathrm{CFU} / \mathrm{ml}$, as determined by plate counting. Each strain was homogeneously inoculated on 1\% agar plates containing Murashige and Skoog (MS) basal salt mixture (Sigma-Aldrich, St. Louis). Eight seeds were sown in each plate and six plates were used for each treatment: control without bacteria, JMP134 wild type, $\mathrm{P}_{\text {lux }}$-lux-GFP, or $\mathrm{P}_{\text {lux }}$-lux-IAA-GFP strains. Plates were placed vertically, sealed with parafilm, and arranged in a 
completely randomized design. The plant growth chamber was run with a cycle of $12 \mathrm{~h}$ of light and $12 \mathrm{~h}$ of darkness and a temperature of $22 \pm 2^{\circ} \mathrm{C} .25$ plantlets from each inoculated or not inoculated treatment were analyzed. Rosette growth was registered photographically using Adobe Photoshop Cs3 software (Adobe Systems Incorporated, San Jose, CA, USA). Root lengths and lateral root numbers were measured directly in harvested plants, and fresh weight was recorded as previously described ${ }^{70}$. Rhizospheric colonization tests were performed using 2-week-old inoculated plants washed in phosphate buffer solution with vortex agitation. Extracted liquid material was serially diluted with Dorn mineral salts medium and grown in Dorn medium plates supplemented with $5 \mathrm{mM}$ benzoate. The CFU/mg FW was determined after $48 \mathrm{~h}$ of incubation at $30^{\circ} \mathrm{C}$. Three biological replicates were carried out.

\section{Confocal microscopy analysis}

To determine rhizosphere colonization by GFP-marked strains, treated and untreated plant root surfaces were examined by confocal microscopy. Confocal microscope images were obtained using Leica TCS LSI confocal laser scanning (Wetzlar, Allemagne), using PLANAPO 5x/0.5 LWD objective.

\section{Statistical analysis}

Data for plant growth parameters were statistically analyzed using one-way analysis of variance. When analysis of variance showed significant treatment effects, Tukey's honestly significant difference $(P<0.05)$ test was applied to make comparisons between treatments. Statistical analyses were performed using the statistical software package STATISTICA (version 6.0; StatSoft Inc., Tulsa, OK, U.S.A.). 


\author{
ASSOCIATED CONTENT \\ Supporting Information \\ Contains further details of supplemental figures and tables. This information is \\ available free of charge via the Internet at http://pubs.acs.org \\ Corresponding Author \\ Email: ana.zuniga@cbs.cnrs.fr
}

\title{
Author contributions:
}

AZ, F de la Fuente, FF, BG designed the experiments. AZ, F de la Fuente and FF performed the experiments. CL performed HPLC experiments. BG, VD, JB, FF, AZ, F de la Fuente aided in interpreting the results. BG, VD, JB provided material source. AZ wrote the manuscript. All authors provided critical feedback and helped shape the research and manuscript. All authors approved the manuscript.

\section{ACKNOWLEDGEMENTS}

We thank J. Lichtman, J. Sanes, and D. Cai (Harvard University) for providing mKate2 DNA. This work was supported by postdoctoral FONDECYT grant 3140031 (to AZ), the FONDECYT grant 1151130, the CONICYT grant FB 00022014, the Millennium Nuclei in "Plant Functional Genomics" grant P/10-062-F and in "Plant Systems and Synthetic Biology" grant NC130030. We thanks PIBS platform of Biocampus Montpellier for the use of HPLC-UV. 


\section{FIGURE LEGENDS}

Figure 1. Engineering a device for positive feedback gene induction using a quorum sensing (QS) system in Cupriavidus pinatubonensis JMP134. (A)

Genetic scheme of QS operon constructions harbored by different strain JMP134 derivatives; $P_{\text {lux }}$-GFP, $P_{\text {lux }}$-luxl-GFP and $P_{\text {lux }}$-luxl-IAA-GFP. Parts of the device design: $\mathrm{P}$ (promoter), RBS (ribosome binding site), Arrow (gene), $\mathrm{T}$ (terminator), for details sequences see Table 1. GFP fluorescence levels over time (B) and growth $\left(\mathrm{OD}_{600 \mathrm{~nm}}\right)(\mathrm{C})$, in response to 0 or $1 \mu \mathrm{M}$ of 3-oxo-C6 homoserine lactone (HSL) in strain $\mathrm{P}_{\mathrm{lux}}$-GFP compared to the autoinduction curve from strain $\mathrm{P}_{\mathrm{lux}}-\mathrm{luxl}-$ GFP without HSL. Each data point was normalized by $\mathrm{OD}_{600 \mathrm{~nm}}$ in (B). Each fluorescence level is accompanied by an additional bar representing the standard deviation of the mean for that particular data set.

Figure 2. Device response to 3-oxo-C6-HSL induction. Flow cytometry contours showing GFP fluorescence plotted as function of cell $O D_{600 n m}$ of strains: $\mathrm{P}_{\text {lux }}$-GFP (A, upper panel), $\mathrm{P}_{\text {lux }}$-luxl-GFP (A, bottom panel) and $\mathrm{P}_{\text {lux }}$-luxl-IAA-GFP (B), induced with $1 \mu \mathrm{M} 3$-oxo-C6-HSL or not. The contour interval are at $2 \%$ of population. The supplementary table T2 show the number of events for each plot. The width of each contour represents forward scatter. 
Figure 3. Beneficial effects in Arabidopsis thaliana plants inoculated by Cupriavidus pinatubonensis JMP134 harboring the engineered device for IAA production under quorum sensing signals. (A) Plant growth in gnotobiotic A. thaliana culture systems inoculated with wild type strain JMP134, $\mathrm{P}_{\text {lux }}$-luxl-GFP or $\mathrm{P}_{\text {lux }}$-luxl-IAA-GFP strains. Growth parameters were measured 3 weeks after inoculation. Bars show mean percentage values with respect to control plants, and the error bars indicate standard deviations from average of three biological replicate experiments for each treatment. Asterisk indicates statistically significant differences between treatments (one-way analysis of variance Tukey's honestly significant difference tests, $P<0.05)$. (B-D) Representative examples of confocal images of root colonization of $A$. thaliana 35S:mKate-LTI6b-Nos $T$ plants by strains: wild type JMP134, without GFP reporter (B); $\mathrm{P}_{\text {lux }}$-luxl-GFP (C); and $\mathrm{P}_{\text {lux }}$ IUXI-IAA-GFP (D). It is possible to observe the GFP produced by strains with activated QS system harboring their respective plasmids. 


\section{REFERENCES}

(1) Parnell, J. J.; Berka, R.; Young, H. A.; Sturino, J. M.; Kang, Y.; Barnhart, D. M.; DiLeo, M. V. From the Lab to the Farm: An Industrial Perspective of Plant Beneficial Microorganisms. Front. Plant Sci. 2016, 7, 1110.

(2) Vassilev, N.; Vassileva, M.; Lopez, A.; Martos, V.; Reyes, A.; Maksimovic, I.; EichlerLöbermann, B.; Malusà, E. Unexploited Potential of Some Biotechnological Techniques for Biofertilizer Production and Formulation. Appl. Microbiol. Biotechnol. 2015, 99 (12), 4983-4996.

(3) Mahanty, T.; Bhattacharjee, S.; Goswami, M.; Bhattacharyya, P.; Das, B.; Ghosh, A.; Tribedi, P. Biofertilizers: A Potential Approach for Sustainable Agriculture Development. Environ. Sci. Pollut. Res. Int. 2017, 24 (4), 3315-3335.

(4) Vitorino, L. C.; Bessa, L. A. Technological Microbiology: Development and Applications. Front. Microbiol. 2017, 8, 827.

(5) Vacheron, J.; Desbrosses, G.; Bouffaud, M.-L.; Touraine, B.; Moënne-Loccoz, Y.; Muller, D.; Legendre, L.; Wisniewski-Dyé, F.; Prigent-Combaret, C. Plant GrowthPromoting Rhizobacteria and Root System Functioning. Front. Plant Sci. 2013, 4, 356.

(6) Andrews., M.; James., E. K.; Cummings., S. P.; Zavalin., A. L.; Vinogradova., V.; McKenzie., B. A. Use of Nitrogen Fixing Bacteria Inoculantts as a Substitute for Nitrogen Fertilizer for Dryland Graminaceous Crops: Progress Made, Mechanisms of Action and Future Potential. Symbiosis 2003, 35 (1), 209-229.

(7) Bruto, M.; Prigent-Combaret, C.; Muller, D.; Moënne-Loccoz, Y. Analysis of Genes Contributing to Plant-Beneficial Functions in Plant Growth-Promoting Rhizobacteria and Related Proteobacteria. Sci. Rep. 2014, 4, 6261.

(8) Couillerot, O.; Combes-Meynet, E.; Pothier, J. F.; Bellvert, F.; Challita, E.; Poirier, M.A.; Rohr, R.; Comte, G.; Moënne-Loccoz, Y.; Prigent-Combaret, C. The Role of the Antimicrobial Compound 2,4-Diacetylphloroglucinol in the Impact of Biocontrol Pseudomonas Fluorescens F113 on Azospirillum Brasilense Phytostimulators. Microbiology 2011, 157 (Pt 6), 1694-1705.

(9) Gera, C.; Srivastava, S. Quorum-Sensing: The Phenomenon of Microbial Communication. Curr. Sci. 2006, 90 (5), 666-676.

(10) Ng, W.-L.; Bassler, B. L. Bacterial Quorum-Sensing Network Architectures. Annu. Rev. Genet. 2009, 43, 197-222.

(11) Solano, C.; Echeverz, M.; Lasa, I. Biofilm Dispersion and Quorum Sensing. Curr. Opin. Microbiol. 2014, 18, 96-104.

(12) Boyer, M.; Wisniewski-Dyé, F. Cell-Cell Signalling in Bacteria: Not Simply a Matter of Quorum. FEMS Microbiol. Ecol. 2009, 70 (1), 1-19.

(13) Asfahl, K. L.; Schuster, M. Social Interactions in Bacterial Cell-Cell Signaling. FEMS Microbiol. Rev. 2017, 41 (1), 92-107.

(14) Hwang, I. Y.; Tan, M. H.; Koh, E.; Ho, C. L.; Poh, C. L.; Chang, M. W. Reprogramming Microbes to Be Pathogen-Seeking Killers. ACS Synth. Biol. 2014, 3 (4), 228-237.

(15) Pai, A.; Srimani, J. K.; Tanouchi, Y.; You, L. Generic Metric to Quantify Quorum Sensing Activation Dynamics. ACS Synth. Biol. 2014, 3 (4), 220-227.

(16) Davis, R. M.; Muller, R. Y.; Haynes, K. A. Can the Natural Diversity of QuorumSensing Advance Synthetic Biology? Front Bioeng Biotechnol 2015, 3, 30.

(17) Ledger, T.; Zúñiga, A.; Kraiser, T.; Dasencich, P.; Donoso, R.; Pérez-Pantoja, D.; 
González, B. Aromatic Compounds Degradation Plays a Role in Colonization of Arabidopsis Thaliana and Acacia Caven by Cupriavidus Pinatubonensis JMP134. Antonie Van Leeuwenhoek 2012, 101 (4), 713-723.

(18) Lykidis, A.; Pérez-Pantoja, D.; Ledger, T.; Mavromatis, K.; Anderson, I. J.; Ivanova, N. N.; Hooper, S. D.; Lapidus, A.; Lucas, S.; González, B.; et al. The Complete Multipartite Genome Sequence of Cupriavidus Necator JMP134, a Versatile Pollutant Degrader. PLoS One 2010, 5 (3), e9729.

(19) Eberl, L. Quorum Sensing in the Genus Burkholderia. Int. J. Med. Microbiol. 2006, 296 (2-3), 103-110.

(20) Basu, S.; Gerchman, Y.; Collins, C. H.; Arnold, F. H.; Weiss, R. A Synthetic Multicellular System for Programmed Pattern Formation. Nature 2005, 434 (7037), 1130-1134.

(21) Scott, S. R.; Hasty, J. Quorum Sensing Communication Modules for Microbial Consortia. ACS Synth. Biol. 2016, 5 (9), 969-977.

(22) Badri, D. V.; Weir, T. L.; van der Lelie, D.; Vivanco, J. M. Rhizosphere Chemical Dialogues: Plant-Microbe Interactions. Curr. Opin. Biotechnol. 2009, 20 (6), 642650.

(23) Dickschat, J. S. Quorum Sensing and Bacterial Biofilms. Nat. Prod. Rep. 2010, 27 (3), 343-369.

(24) Marchand, N.; Collins, C. H. Synthetic Quorum Sensing and Cell-Cell Communication in Gram-Positive Bacillus Megaterium. ACS Synth. Biol. 2016, 5 (7), 597-606.

(25) Wang, Z.; Wu, X.; Peng, J.; Hu, Y.; Fang, B.; Huang, S. Artificially Constructed Quorum-Sensing Circuits Are Used for Subtle Control of Bacterial Population Density. PLoS One 2014, 9 (8), e104578.

(26) Chu, T.; Huang, Y.; Hou, M.; Wang, Q.; Xiao, J.; Liu, Q.; Zhang, Y. In Vivo Programmed Gene Expression Based on Artificial Quorum Networks. Appl. Environ. Microbiol. 2015, 81 (15), 4984-4992.

(27) Servinsky, M. D.; Terrell, J. L.; Tsao, C.-Y.; Wu, H.-C.; Quan, D. N.; Zargar, A.; Allen, P. C.; Byrd, C. M.; Sund, C. J.; Bentley, W. E. Directed Assembly of a Bacterial Quorum. ISME J. 2016, 10 (1), 158-169.

(28) Liu, Q.; Schumacher, J.; Wan, X.; Lou, C.; Wang, B. Orthogonality and Burdens of Heterologous AND Gate Gene Circuits in E. Coli. ACS Synth. Biol. 2018, 7 (2), 553564.

(29) Sayut, D. J.; Kambam, P. K. R.; Sun, L. Noise and Kinetics of LuxR Positive Feedback Loops. Biochem. Biophys. Res. Commun. 2007, 363 (3), 667-673.

(30) Bansal, K.; Yang, K.; Nistala, G. J.; Gennis, R. B.; Bhalerao, K. D. A Positive Feedback-Based Gene Circuit to Increase the Production of a Membrane Protein. J. Biol. Eng. 2010, 4, 6.

(31) Heilmann, S.; Krishna, S.; Kerr, B. Why Do Bacteria Regulate Public Goods by Quorum Sensing?-How the Shapes of Cost and Benefit Functions Determine the Form of Optimal Regulation. Front. Microbiol. 2015, 6, 767.

(32) Hense, B. A.; Schuster, M. Core Principles of Bacterial Autoinducer Systems. Microbiol. Mol. Biol. Rev. 2015, 79 (1), 153-169.

(33) Grandclément, C.; Tannières, M.; Moréra, S.; Dessaux, Y.; Faure, D. Quorum Quenching: Role in Nature and Applied Developments. FEMS Microbiol. Rev. 2016, 40 (1), 86-116.

(34) Hense, B. A.; Kuttler, C.; Müller, J.; Rothballer, M.; Hartmann, A.; Kreft, J.-U. Does 
Efficiency Sensing Unify Diffusion and Quorum Sensing? Nat. Rev. Microbiol. 2007, 5 (3), 230-239.

(35) Dong, Y.-H.; Zhang, L.-H. Quorum Sensing and Quorum-Quenching Enzymes. J. Microbiol. 2005, 43 Spec No, 101-109.

(36) Lee, J.; Wu, J.; Deng, Y.; Wang, J.; Wang, C.; Wang, J.; Chang, C.; Dong, Y.; Williams, P.; Zhang, L.-H. A Cell-Cell Communication Signal Integrates Quorum Sensing and Stress Response. Nat. Chem. Biol. 2013, 9 (5), 339-343.

(37) Zúñiga, A.; Poupin, M. J.; Donoso, R.; Ledger, T.; Guiliani, N.; Gutiérrez, R. A.; González, B. Quorum Sensing and Indole-3-Acetic Acid Degradation Play a Role in Colonization and Plant Growth Promotion of Arabidopsis Thaliana by Burkholderia Phytofirmans PsJN. Mol. Plant. Microbe. Interact. 2013, 26 (5), 546-553.

(38) Verbon, E. H.; Liberman, L. M. Beneficial Microbes Affect Endogenous Mechanisms Controlling Root Development. Trends Plant Sci. 2016, 21 (3), 218-229.

(39) Mauchline, T. H.; Malone, J. G. Life in Earth - the Root Microbiome to the Rescue? Curr. Opin. Microbiol. 2017, 37, 23-28.

(40) Battini, F.; Grønlund, M.; Agnolucci, M.; Giovannetti, M.; Jakobsen, I. Facilitation of Phosphorus Uptake in Maize Plants by Mycorrhizosphere Bacteria. Sci. Rep. 2017, 7 (1), 4686.

(41) Idris, E. E.; Iglesias, D. J.; Talon, M.; Borriss, R. Tryptophan-Dependent Production of Indole-3-Acetic Acid (IAA) Affects Level of Plant Growth Promotion by Bacillus Amyloliquefaciens FZB42. Mol. Plant. Microbe. Interact. 2007, 20 (6), 619-626.

(42) Kochar, M.; Upadhyay, A.; Srivastava, S. Indole-3-Acetic Acid Biosynthesis in the Biocontrol Strain Pseudomonas Fluorescens Psd and Plant Growth Regulation by Hormone Overexpression. Res. Microbiol. 2011, 162 (4), 426-435.

(43) Shao, J.; Li, S.; Zhang, N.; Cui, X.; Zhou, X.; Zhang, G.; Shen, Q.; Zhang, R. Analysis and Cloning of the Synthetic Pathway of the Phytohormone Indole-3-Acetic Acid in the Plant-Beneficial Bacillus Amyloliquefaciens SQR9. Microb. Cell Fact. 2015, 14, 130.

(44) Carlos, M.-H. J.; Stefani, P.-V. Y.; Janette, A.-M.; Melani, M.-S. S.; Gabriela, P.-O. Assessing the Effects of Heavy Metals in ACC Deaminase and IAA Production on Plant Growth-Promoting Bacteria. Microbiol. Res. 2016, 188-189, 53-61.

(45) Liu, Y.; Chen, L.; Zhang, N.; Li, Z.; Zhang, G.; Xu, Y.; Shen, Q.; Zhang, R. PlantMicrobe Communication Enhances Auxin Biosynthesis by a Root-Associated Bacterium, Bacillus Amyloliquefaciens SQR9. Mol. Plant. Microbe. Interact. 2016, 29 (4), 324-330.

(46) Imada, E. L.; Rolla Dos Santos, A. A. de P.; Oliveira, A. L. M. de; Hungria, M.; Rodrigues, E. P. Indole-3-Acetic Acid Production via the Indole-3-Pyruvate Pathway by Plant Growth Promoter Rhizobium Tropici CIAT 899 Is Strongly Inhibited by Ammonium. Res. Microbiol. 2017, 168 (3), 283-292.

(47) Kamilova, F.; Kravchenko, L. V.; Shaposhnikov, A. I.; Azarova, T.; Makarova, N.; Lugtenberg, B. Organic Acids, Sugars, and L-Tryptophane in Exudates of Vegetables Growing on Stonewool and Their Effects on Activities of Rhizosphere Bacteria. Mol. Plant. Microbe. Interact. 2006, 19 (3), 250-256.

(48) Cerboneschi, M.; Decorosi, F.; Biancalani, C.; Ortenzi, M. V.; Macconi, S.; Giovannetti, L.; Viti, C.; Campanella, B.; Onor, M.; Bramanti, E.; et al. Indole-3Acetic Acid in Plant-Pathogen Interactions: A Key Molecule for in Planta Bacterial Virulence and Fitness. Res. Microbiol. 2016, 167 (9-10), 774-787.

(49) Ortíz-Castro, R.; Martínez-Trujillo, M.; López-Bucio, J. N-Acyl-L-Homoserine Lactones: A Class of Bacterial Quorum-Sensing Signals Alter Post-Embryonic Root 
(50) Ahemad., M.; Khan., M. S. Assessment of Plant Growth Promoting Activities of Rhizobacterium Pseudomonas Putida under Insecticide-Stress. Microbiology Journal 2011, 1, 54-64.

(51) Boiero, L.; Perrig, D.; Masciarelli, O.; Penna, C.; Cassán, F.; Luna, V. Phytohormone Production by Three Strains of Bradyrhizobium Japonicum and Possible Physiological and Technological Implications. Appl. Microbiol. Biotechnol. 2007, 74 (4), 874-880.

(52) Trabelsi, D.; Mhamdi, R. Microbial Inoculants and Their Impact on Soil Microbial Communities: A Review. Biomed Res. Int. 2013, 2013, 863240.

(53) Perrig, D.; Boiero, M. L.; Masciarelli, O. A.; Penna, C.; Ruiz, O. A.; Cassán, F. D.; Luna, M. V. Plant-Growth-Promoting Compounds Produced by Two Agronomically Important Strains of Azospirillum Brasilense, and Implications for Inoculant Formulation. Appl. Microbiol. Biotechnol. 2007, 75 (5), 1143-1150.

(54) Ahemad, M.; Khan - Emirates Journal of Food and, M. S.; 2012. Ecological Assessment of Biotoxicity of Pesticides towards Plant Growth Promoting Activities of Pea (Pisum Sativum)-Specific Rhizobium Sp. Strain MRP1. search.proquest.com 2012.

(55) Ramos-González, M. I.; Campos, M. J.; Ramos, J. L. Analysis of Pseudomonas Putida KT2440 Gene Expression in the Maize Rhizosphere: In Vivo [corrected] Expression Technology Capture and Identification of Root-Activated Promoters. J. Bacteriol. 2005, 187 (12), 4033-4041.

(56) Cutler, S. R.; Ehrhardt, D. W.; Griffitts, J. S.; Somerville, C. R. Random GFP::cDNA Fusions Enable Visualization of Subcellular Structures in Cells of Arabidopsis at a High Frequency. Proc. Natl. Acad. Sci. U. S. A. 2000, 97 (7), 3718-3723.

(57) Kurup, S.; Runions, J.; Köhler, U.; Laplaze, L.; Hodge, S.; Haseloff, J. Marking Cell Lineages in Living Tissues. Plant J. 2005, 42 (3), 444-453.

(58) Shcherbo, D.; Murphy, C. S.; Ermakova, G. V.; Solovieva, E. A.; Chepurnykh, T. V.; Shcheglov, A. S.; Verkhusha, V. V.; Pletnev, V. Z.; Hazelwood, K. L.; Roche, P. M.; et al. Far-Red Fluorescent Tags for Protein Imaging in Living Tissues. Biochem. J 2009, 418 (3), 567-574.

(59) Dorn, E.; Hellwig, M.; Reineke, W.; Knackmuss, H. J. Isolation and Characterization of a 3-Chlorobenzoate Degrading Pseudomonad. Arch. Microbiol. 1974, 99 (1), 6170.

(60) Canton, B.; Labno, A.; Endy, D. Refinement and Standardization of Synthetic Biological Parts and Devices. Nat. Biotechnol. 2008, 26 (7), 787-793.

(61) Silva-Rocha, R.; Martínez-García, E.; Calles, B.; Chavarría, M.; Arce-Rodríguez, A.; de Las Heras, A.; Páez-Espino, A. D.; Durante-Rodríguez, G.; Kim, J.; Nikel, P. I.; et al. The Standard European Vector Architecture (SEVA): A Coherent Platform for the Analysis and Deployment of Complex Prokaryotic Phenotypes. Nucleic Acids Res. 2013, 41 (Database issue), D666-D675.

(62) Martínez-García, E.; Aparicio, T.; Goñi-Moreno, A.; Fraile, S.; de Lorenzo, V. SEVA 2.0: An Update of the Standard European Vector Architecture for de-/reConstruction of Bacterial Functionalities. Nucleic Acids Res. 2015, 43 (Database issue), D1183-D1189.

(63) Wright, O.; Delmans, M.; Stan, G.-B.; Ellis, T. GeneGuard: A Modular Plasmid System Designed for Biosafety. ACS Synth. Biol. 2015, 4 (3), 307-316.

(64) Goñi-Moreno, Á.; Benedetti, I.; Kim, J.; de Lorenzo, V. Deconvolution of Gene Expression Noise into Spatial Dynamics of Transcription Factor-Promoter Interplay. 
ACS Synth. Biol. 2017, 6 (7), 1359-1369.

(65) Sánchez-Pascuala, A.; de Lorenzo, V.; Nikel, P. I. Refactoring the EmbdenMeyerhof-Parnas Pathway as a Whole of Portable GlucoBricks for Implantation of Glycolytic Modules in Gram-Negative Bacteria. ACS Synth. Biol. 2017, 6 (5), 793805.

(66) Gibson, D. G.; Young, L.; Chuang, R.-Y.; Venter, J. C.; Hutchison, C. A., 3rd; Smith, H. O. Enzymatic Assembly of DNA Molecules up to Several Hundred Kilobases. Nat. Methods 2009, 6 (5), 343-345.

(67) Boisnard-Lorig, C.; Colon-Carmona, A.; Bauch, M.; Hodge, S.; Doerner, P.; Bancharel, E.; Dumas, C.; Haseloff, J.; Berger, F. Dynamic Analyses of the Expression of the HISTONE::YFP Fusion Protein in Arabidopsis Show That Syncytial Endosperm Is Divided in Mitotic Domains. Plant Cell 2001, 13 (3), 495-509.

(68) Cai, D.; Cohen, K. B.; Luo, T.; Lichtman, J. W.; Sanes, J. R. Improved Tools for the Brainbow Toolbox. Nat. Methods 2013, 10 (6), 540-547.

(69) Clough, S. J.; Bent, A. F. Floral Dip: A Simplified Method for AgrobacteriumMediated Transformation of Arabidopsis Thaliana. Plant J. 1998, 16 (6), 735-743.

(70) Sessitsch, A.; Coenye, T.; Sturz, A. V.; Vandamme, P.; Barka, E. A.; Salles, J. F.; Van Elsas, J. D.; Faure, D.; Reiter, B.; Glick, B. R.; et al. Burkholderia Phytofirmans Sp. Nov., a Novel Plant-Associated Bacterium with Plant-Beneficial Properties. Int. J. Syst. Evol. Microbiol. 2005, 55 (Pt 3), 1187-1192. 
Age 25 of 28 ACS Synthetic Biology

1

2

3

4

5

6

7

8

9

10

11

12

13

14

15

16

B

19

20

21

22

23

24

25

26

27

28

29

30

31

32

33

34

35

30

38

39

40

41

42

43

44

45

46

47

48

49

50

51

52

53

54

55
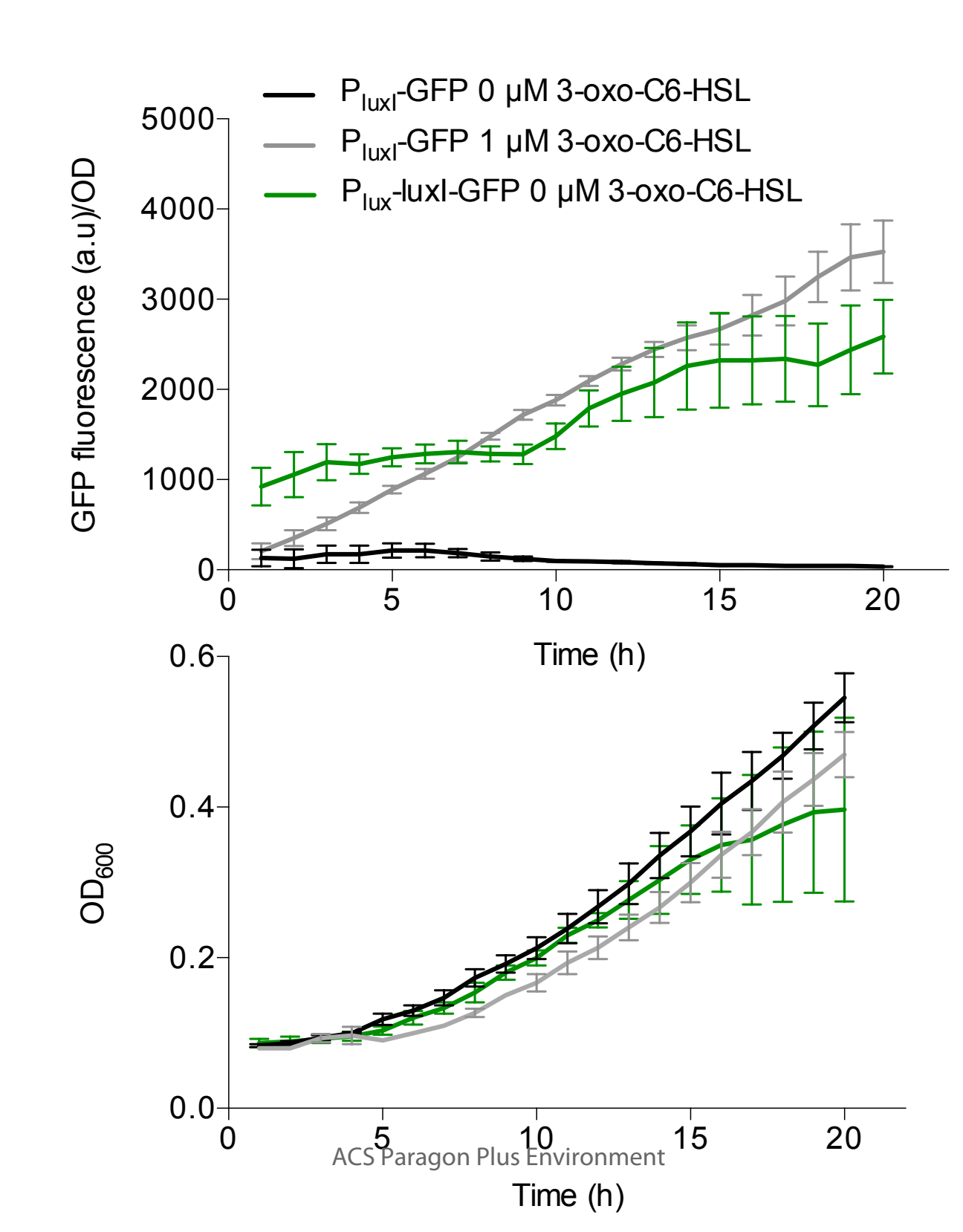

$P_{\text {lux }}$-luxI-IAA-GFP

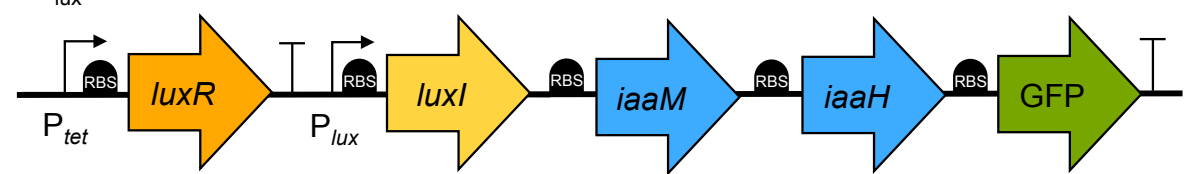

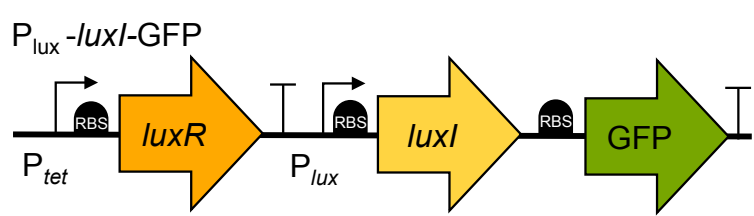
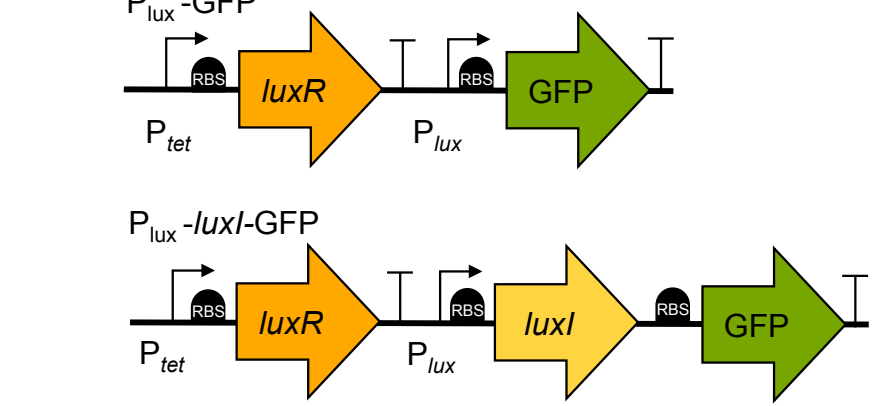

.

.




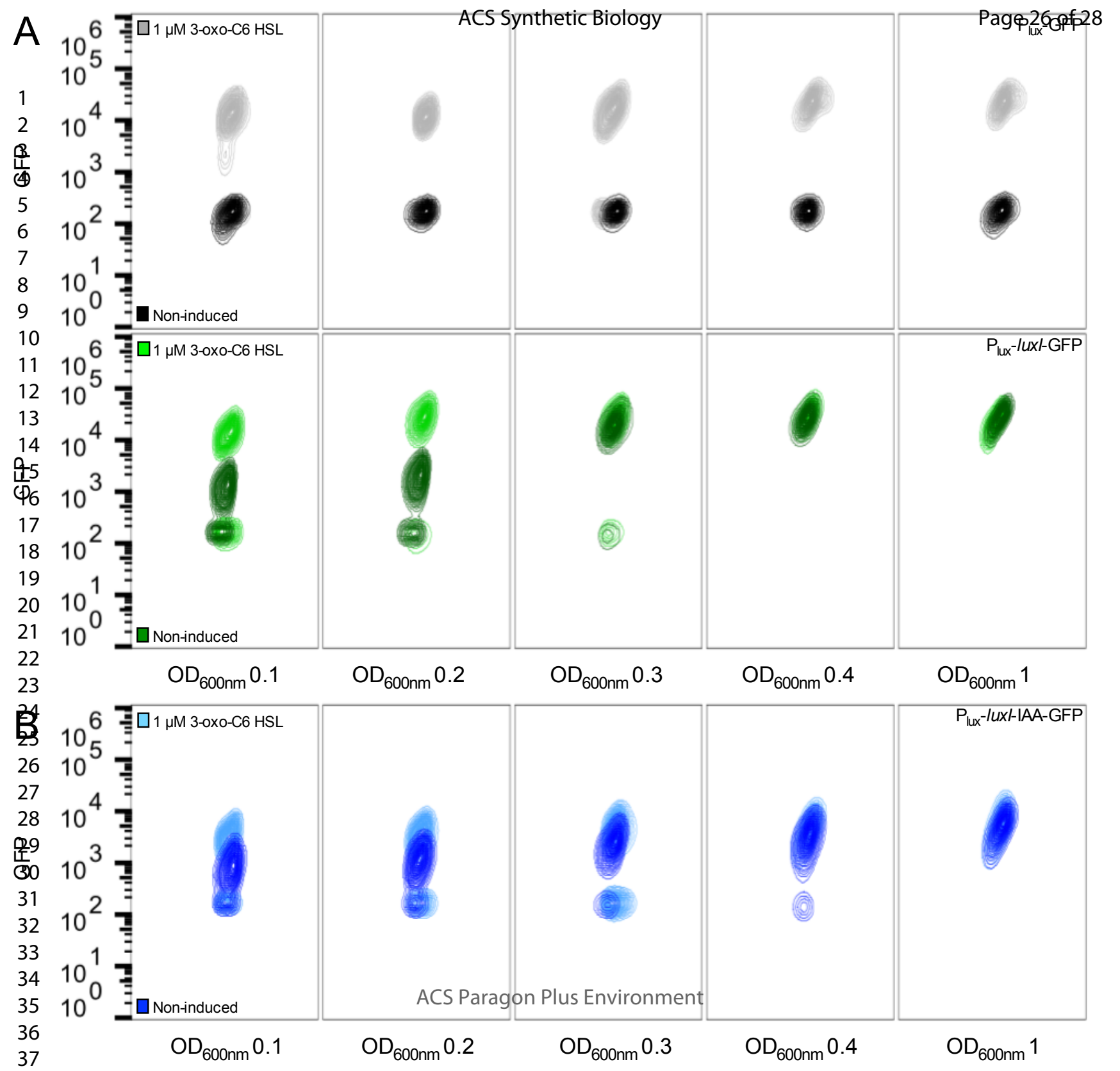




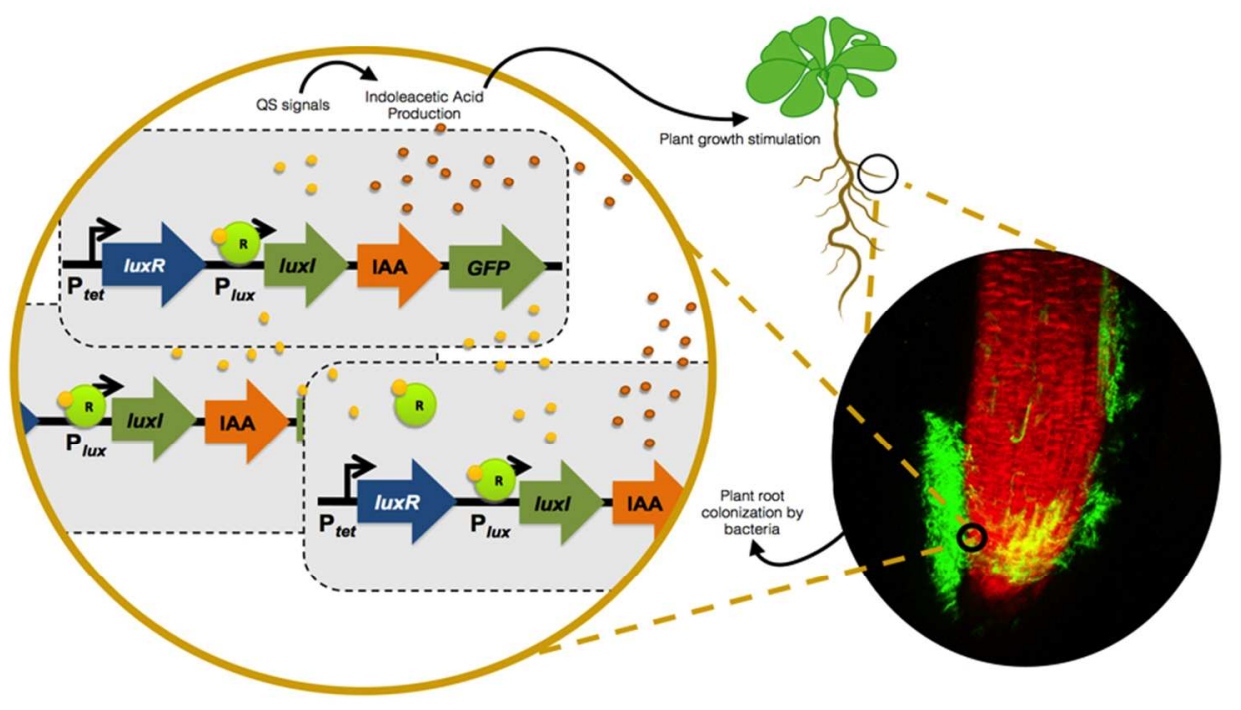

For Table of Contents Use Only

$82 \times 58 \mathrm{~mm}(300 \times 300$ DPI $)$ 